\title{
Invisible Support and Adjustment to Stress
}

\author{
Niall Bolger \\ New York University
}

\author{
Adam Zuckerman \\ International Survey Research Corporation, Chicago, Illinois
}

\author{
Ronald C. Kessler \\ Harvard Medical School
}

\begin{abstract}
Although there is abundant evidence that perceived availability of support buffers the effects of stressors on mental health, the relatively meager research on support transactions has failed to show an association between actual receipt of support and adjustment to stressors. The authors examined a possible explanation for this inconsistency, that awareness of receiving support entails an emotional cost and that the most effective support is unnoticed by the recipient. Using data from a daily diary study of support provision and receipt in couples, the authors show that many transactions reported by supporters are not reported by recipients. They also show that these invisible support transactions promote adjustment to a major stressor.
\end{abstract}

It is now well established that perceptions of social support availability predict better adjustment to stressful events (Cohen, 1992; Hobfoll \& Vaux, 1993; House, Landis, \& Umberson, 1988; Sarason, Sarason, \& Gurung, 1997; Stroebe \& Stroebe, 1996; Wills, 1990). It is less clear, however, how these protective effects come about and thus how one might intervene to enhance support during times of stress. Given this uncertainty, social support researchers have increasingly turned their attention to identifying the specific interpersonal processes thought to underlie social support availability effects (Cutrona, 1986; Cutrona \& Suhr, 1994; Eckenrode, 1983; Eckenrode \& Wethington, 1990; Gottlieb, 1988; Heller, Swindle \& Dusenbury, 1986; Reis, 1984).

Although this line of investigation is still relatively new, studies up to now have found that actual support transactions do not improve adjustment to stressful life experiences (Barrera, 1986; Bolger, Foster, Vinokur, \& Ng, 1996; B. B. Brown, 1978; DunkelSchetter \& Bennett, 1990; Eckenrode \& Wethington, 1990; Lieberman, 1986; Wethington \& Kessler, 1986). Indeed, most studies have documented that support receipt is either associated with poor adjustment or, at best, leaves the recipient no better off than if support had not been received.

Niall Bolger, Department of Psychology, New York University; Adam Zuckerman, International Survey Research Corporation, Chicago, Illinois; Ronald C. Kessler, Department of Health Care Policy, Harvard Medical School.

This research was supported in part by National Institute of Mental Health Grant MH60366. We are grateful to David Amarel, Jessica Cameron, James Coyne, Geraldine Downey, Andrew Fuligni, Diane Hughes, Julie Lewis, Edward Seidman, Beth Shinn, and Patrick Shrout for comments on previous drafts of this article.

Correspondence concerning this article should be addressed to Niall Bolger, Social-Personality Program, Department of Psychology, New York University, 6 Washington Place, 7th Floor, New York, New York 10003. Electronic mail may be sent to bolger@psych.nyu.edu.
We do not yet understand why receiving support appears to be ineffective in reducing distress, although three possibilities have been suggested as explanations. One is that people who receive support are under more stress than those who do not receive support. Consistent with this view, Barrera (1986) has shown that the seemingly bad effect of receiving support on mental health is substantially reduced when individual differences in stress severity are controlled. A second possibility is that people's attempts to give support may be miscarried; that is, their well-intentioned efforts may fail to be helpful or may even make matters worse for the person under stress. Coyne, Wortman, and Lehman (1988) documented that this kind of miscarried helping is not uncommon. A third possible reason why received support may be ineffective is that receiving help entails a cost to self-esteem because it makes salient to recipients that they are having difficulties coping with a stressor (Fisher, Nadler, \& Whitcher-Alagna, 1982; Shapiro, 1978).

Whatever the explanation, it is hard to reconcile the ineffectiveness of received support with the well-established buffering effects of more traditional measures of perceived support availability. If received support is ineffective, why is it that perceived support availability buffers the effects of stress on health?

To reconcile this inconsistency, it has been proposed that the stress-protective effects of perceived support availability do not involve actual support transactions. B. B. Brown (1978), for example, found that people with the best social and personal resources-those who are known to adjust better to stress-are the least likely to report seeking support when they are under stress. Thus, the perception that one could get support if one wanted it might be sufficient to help one deal with many stressful situations. Advancing this view, Wethington and Kessler (1986) argued that this perception of support availability may either be comforting in itself or provide the kind of psychological safety net that helps motivate self-reliant coping efforts. In either case, the best psy- 
chological outcomes appear to be associated with perceiving that support is available rather than seeking it out.

Although Wethington and Kessler's (1986) account explains how perceived support availability can have a beneficial effect independent of enacted support, it does not explain why enacted support appears to have a neutral or negative effect on adjustment to stress. To make sense of this finding, our approach in this article is to posit that support transactions are most likely to be beneficial when they are accomplished without being visible to the recipient. This proposition is in line with Lieberman's (1986) suggestion that the high-resource group in the B. B. Brown (1978) study may have been getting support so smoothly that it was invisible to them. What do we mean by invisible in this context? There are at least two types of situations in which support may be invisible to recipients. First, the supportive act may occur outside of the recipient's awareness, for example, when one spouse takes care of unexpected housework without telling the other. Second, the recipient may be aware of the act but may not code it as support, for example, when a friend purposefully gives advice in an indirect way so as not to draw attention to the recipient's distress or his or her inability to deal with the stressful situation.

Such invisible supportive acts would not only buffer the effects of stressors on the recipient, but they would also circumvent any self-esteem or self-efficacy cost of receiving help. Perhaps the reason, then, why traditional received support measures do not appear to be beneficial is that they confound two opposing effects, the benefits people experience when support is provided to them and the costs they experience when they perceive-accurately or inaccurately - that support has been provided.

If recipient accounts of support confound these two opposing effects, then such measures alone will never uncover the benefits of receiving support. However, combining recipient accounts with provider accounts may provide a way of doing so. It is known that provider and recipient accounts are, at best, only moderately correlated (Abbey, Andrews, \& Halman, 1995; Antonucci \& Israel, 1986; Coriell \& Cohen, 1995). Using both measures may allow one to disentangle the benefits of support, which we hypothesized are captured by the unique effects of the provider's account of support, from the costs of support, which we hypothesized are captured by the unique effect of the recipient perceiving that support has occurred.

Figure 1 illustrates these ideas. It shows that support provision and receipt are positively related, reflecting the idea that providers and recipients are likely to agree that instances of support have

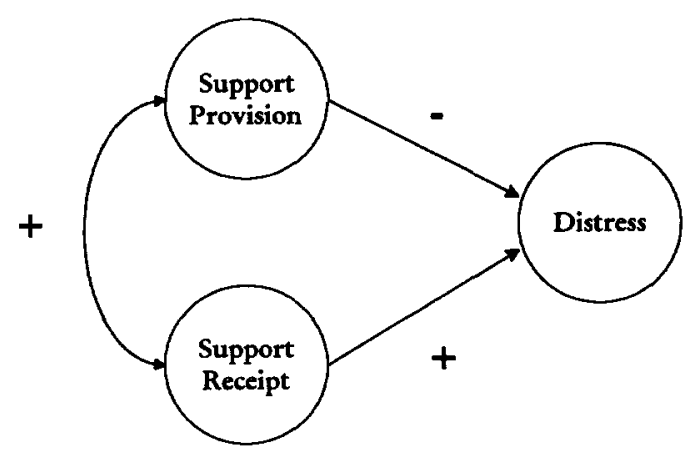

Figure 1. Model of support effects in stressful situations. occurred. However, it also shows that provider and recipient accounts have unique and opposite effects on distress in stressful situations. This causal pattern implies that the most effective type of support transaction is one in which the provider reports providing support but the recipient does not believe that support has occurred, namely, when the benefits of provision are accrued and the costs of receipt are avoided. This is the type of support that we refer to as invisible. By the same token, this causal pattern implies that the least effective type of support is one in which the provider does not report providing support but the recipient reports receiving it.

To test these ideas, we conducted a daily diary study that questioned couples about support given and received across a series of weeks. Specifically, we studied 68 couples in which one member was preparing to undergo a major stressful event, the New York State Bar Examination. This is a 2-day examination that all prospective lawyers must pass before practicing law in New York State. Over a 35-day period leading up to and beyond the examination, examinees and partners in these couples each completed a brief daily questionnaire. Partners reported their daily provision of emotional support, and examinees reported their daily receipt of emotional support as well as their daily levels of anxiety and depression. We focused on emotional support in the current study because emotional support has been consistently found to be the most effective in reducing distress (Cohen \& Wills, 1985; Stroebe \& Stroebe, 1996).

We chose to study couples facing this major stressor not only because it allowed us to obtain provider and recipient accounts of enacted support, but also because it allowed us to rule out two other possible explanations for the absence of enacted support effects in prior studies. First, because the objective features of the stressor are the same for each examinee, our design allowed us to circumvent a pervasive problem in identifying enacted support effects, namely that enacted support is confounded by unmeasured differences in stressor severity (Barrera, 1986).

Second, we could examine the validity of the miscarried-helping explanation, that is, that many well-intentioned support attempts fail to meet the needs of those under stress and may even make matters worse (Coyne et al., 1988). If support attempts are frequently miscarried, then our prediction that adjustment will be best when support is given and invisible to the recipient should not be borne out. Rather, adjustment should be best in situations in which the recipient rather than the provider feels that support has occurred.

In summary, then, our study enabled us to investigate a particular explanation for the failure of prior studies to find beneficial effects of enacted support. Our goal was to determine whether these beneficial effects are confined to acts that are invisible to recipients and therefore cannot be captured by traditional measures of enacted support. We did so while at the same time considering two other possible explanations, one based on unmeasured differences in stressor severity and the other based on the view that support attempts are often miscarried.

\section{Method}

\section{Design and Sample}

To recruit couples, we asked officials at all 15 New York State law schools to distribute recruitment letters to their graduating students. Nine of 
the schools agreed to do so. The recruitment letters described the study and specified our inclusion criteria. To be eligible, examinees had to be in a romantic relationship with a partner of the opposite sex for at least the last 6 months and had to expect to be living with their partner at the time of the study. Couples in which both members were taking the test were excluded from participation. Our recruitment letters also indicated that couples completing all materials would receive $\$ 50$.

Because information about the relationship status of graduating law students was not available from law schools, we distributed recruitment letters to all final-year students. Each letter was accompanied by a postcard to be returned to the investigators if the student met the study's eligibility requirements and was interested in finding out more about the study. One hundred forty postcards were returned. ${ }^{1}$ Interested students were then contacted by phone and given more complete details of the study. Of these, 99 couples agreed to participate.

Two months before the examination, couples were sent a background questionnaire that obtained a variety of demographic, social, and personality information not relevant to the current investigation. One month before the examination, couples were sent two booklets of seven daily diaries, one each for the examinee and partner. The daily diary forms for the examinee and partner were identical and consisted of a single sheet of paper. The entire form was designed to be completed in less than $5 \mathrm{~min}$, and participants were instructed to complete a diary form each day at bedtime. The diary period ran from 32 days before to 3 days after the examination. A daily diary procedure such as this is well suited to documenting the effect of support on adjustment because it allows investigators to obtain reports of stressors, support, and distress near the time they occur, thereby minimizing retrospective recall problems (Eckenrode \& Bolger, 1997). After completing the 1st week of diaries, participants returned the diary booklet to the investigators using an included prestamped envelope. This procedure was repeated for the entire 5 weeks of the diary period.

Of the 99 couples who initially agreed to participate, a final sample of 68 couples $(69 \%)$ completed all of the materials. Of this final sample, 45 couples $(66 \%)$ had male examinees. Examinee mean age was 29.4 years $(S D=5.1)$, and partner mean age was $29.5(S D=5.9)$. Two thirds of the couples were married, and couples had been living together for an average of 3.3 years $(S D=3.8)$. Eighty-one percent of partners had at least a BA-level education.

Our focus in this article is on the 32 diary days leading up to and including the examination; we did not analyze data from the 3 days following the event. Complete data were obtained on 2,138 , or $98 \%$, of the $2,176(68 \times 32)$ couple-days potentially available for analysis. Thus, the proportion of completed daily diary reports was very high.

\section{Measures}

Examinee distress. Examinee anxiety and depression were measured daily with items from the Profile of Mood States (Lorr \& McNair, 1971). For each affect, the four highest loading items from a factor analysis conducted by Lorr and McNair (1971) were used. The items tapping anxiety were "on edge," "uneasy," "anxious," and "nervous." The items tapping depression were "sad," "discouraged," "hopeless," and "worthless." Examinees were asked to rate the extent to which they had felt or experienced these feelings in the past $24 \mathrm{hr}$. They responded by circling the appropriate number on a 5-point scale ranging from not at all (0) to extremely (4). Daily scores for each affect were obtained by averaging the ratings of the relevant items.

Support provision and receipt. Partners' provision of emotional support to the examinees was assessed on each diary day. This measure consisted of a single item, in which each partner reported whether he or she had "listened to and comforted" the examinee within the previous $24 \mathrm{hr}$. This dichotomous variable was coded .5 if partners reported providing support and -.5 if they did not. Similarly, each day examinees completed a parallel item, in which they reported whether they had received emotional support (as defined above) from their partners. Again this variable was coded .5 if examinees reported receiving support and -.5 if they did not.

The bar examination as a stressor. Our prospective design was intended to capture increases in the perceived threat of the bar examination as the event approached. In particular, we expected that the final week before the examination would be a time of high threat, when the examination was imminent and the possibilities for further preparatory study were almost over. Preliminary inspection of our data revealed that, as was found in a previous study of students preparing to take the Medical College Admission Test (Bolger \& Eckenrode, 1991), appreciable increases in distress were evident only in the final week before the examination. Therefore, to distinguish a period of high threat from a period of more moderate threat, we divided the preexamination period into two phases, one involving the first 25 days of the diary period and the other involving Days 26 to 32. For analysis purposes (see Multilevel Statistical Model), Phase 1 was coded -.5 and Phase 2 was coded .5. The mean levels of anxiety in the first and second phases were 1.83 and 2.62 , respectively, paired $t(67)=18.87, p<.001$. Comparable means for depression were 0.58 and 0.70 , paired $t(67)=5.06, p<.001$.

\section{Multilevel Statistical Model}

The goal of the analysis was to examine the stress-protective effect of enacted support, defined as the reduction in the relationship between stressor onset and distressed mood as a function of supportive interactions with one's partner. As discussed earlier, we hypothesized that the unique effect of support from the provider's perspective would be to reduce the negative effects of a stressor, whereas the unique effect of support from the recipient's perspective would be to increase its effects.

The analysis was accomplished using a multilevel or hierarchical linear model (Bryk \& Raudenbush, 1992; Goldstein, 1995; Kenny, Kashy, \& Bolger, 1998; Kreft \& De Leeuw, 1998; Snijders \& Bosker, 1999). A multilevel model allowed us to obtain separate estimates of the effects of support provision and receipt on adjustment to the bar examination for each couple and to efficiently aggregate these estimates such that results for the average couple were obtained. In addition, it allowed us to test the possibility that couples differ significantly in these effects and to take account of this variability in constructing tests of significance.

Our statistical model specifies that each couple in the population has its own characteristic relationship between support provision and receipt and adjustment to a stressor, in this case, the approach of the bar examination. Note that a within-couple analysis approach ensures that any betweencouples factors, such as average examinee distress or personality, cannot account for any associations found (see Kenny et al., 1998, for a discussion of this point).

Because cross-sectional associations between support and adjustment are likely to reflect in part the effects of adjustment on support (as found, e.g., by Bolger et al., 1996), we focused on longitudinal associations, specifically, those with a 1-day lag. ${ }^{2}$ Thus, support provision and receipt and their interactions with stressor phase on day $t$ are all hypothesized to affect change in distress from day $t$ to day $t+1$. To rule out the possibility that any lagged effect of support on adjustment might be an artifact of initial adjustment (see Bolger et al., 1996), initial distress was included in the model as a control variable. In such a model the dependent variable can be interpreted as residualized change in distress from day $t$ to day $t+1$ (Kessler \& Greenberg, 1981).

The analysis model for each couple can be written as follows:

\footnotetext{
${ }^{\mathrm{I}}$ Note that because the proportion of graduating law students who met our inclusion criteria was unknown, the number of returned postcards cannot be used to calculate response rates.

${ }^{2}$ In preliminary analyses we examined 2- and 3-day time lags, but we found no evidence of effects beyond a 1-day lag.
} 


$$
\begin{gathered}
\Delta D_{t+1}=b_{0}+b_{1} D_{t}+b_{2} S_{t}+b_{3} P_{t}+b_{4} R_{t} \\
+b_{5}\left(P_{t} \times S_{t}\right)+b_{6}\left(R_{t} \times S_{t}\right)+e_{t+1},
\end{gathered}
$$

where $\Delta D_{t+1}$ is the change in examinee's distress between day $t$ and day $t+1 ; D_{t}$ is the examinee's distress on day $t$ (with the grand mean across all couple-days subtracted); $S_{t}$ is the stressor phase (coded -.5 for the first 25 days of the diary period and .5 for the final week up to and including the examination $\left.{ }^{3}\right) ; P_{t}$ is the partner's report of providing emotional support on day $t$ (coded .5 if the partner reported providing support and -.5 if he or she did not); $R_{t}$ is the examinee's report of receiving emotional support on day $t$ (coded .5 if the examinee reported receiving support and -.5 if he or she did not); $\left(P_{t} \times S_{t}\right)$ and $\left(R_{t} \times S_{t}\right)$ are the interactions between phase and the provision and receipt of support on day $t$, respectively; and $e_{t+1}$ is a residual component of change in the examinee's distress. The coefficient $b_{0}$ is the regression intercept, and the coefficients $b_{1}$ through $b_{6}$ are the effects of the six independent variables.

We hypothesized that the coefficient for $\left(P_{t} \times S_{t}\right)$ would be negative, reflecting that support provision reduces the effect of the stressor on distress. In contrast, we hypothesized that the coefficient for $\left(R_{t} \times S_{t}\right)$ would be positive, reflecting that support receipt exacerbates the effect of the stressor on distress.

Although our model allowed for each couple to have unique estimates of support effects, the focus of the current study was on support effects for the average couple. To obtain estimates of these effects, we used a maximum likelihood (ML) approach, as implemented in SAS Institute's PROC MIXED software (Littell, Milliken, Stroup, \& Wolfinger, 1996; SAS Institute, 1997; see Kenny et al., 1998, for a discussion of alternative approaches to estimation of these models). Thus, the results presented for Equation 1 are ML estimates for the average couple.

\section{Results}

Table 1 shows the frequency of emotional support provision and receipt and the degree of concordance between the two. On $65 \%$ of the days on which partners reported providing support, examinees agreed that the support had been provided. On $56 \%$ of the days on which partners did not report providing support, examinees agreed that it had not been provided. In all, concordant days accounted for $61 \%$ of diary days. Although these results show that there was appreciable agreement between partners on the occurrence of emotional support, they also demonstrate that providers and recipients often had discordant perceptions of such support interactions.

We next examined the effects of support provision and receipt on adjustment in the two diary phases, as specified in Equation 1. We estimated this equation twice, once for each of the distress variables, anxiety and depression. ${ }^{4}$ Recall that phase, emotional support provision, and emotional support receipt were effect coded

Table 1

Partner's Report of Emotional Support Provision by Examinee's

\begin{tabular}{|c|c|c|c|c|c|c|}
\hline \multirow{3}{*}{$\begin{array}{l}\text { Support } \\
\text { receipt }\end{array}$} & \multicolumn{4}{|c|}{ Support provision } & & \\
\hline & \multicolumn{2}{|c|}{ No } & \multicolumn{2}{|c|}{ Yes } & \multicolumn{2}{|c|}{ Total } \\
\hline & $N$ & $\%$ & $N$ & $\%$ & $N$ & $\%$ \\
\hline No & 503 & 56 & 434 & 35 & 937 & 44 \\
\hline Yes & 395 & 44 & 806 & 65 & 1,201 & 56 \\
\hline Total & 898 & 100 & 1,240 & 100 & 2,138 & 100 \\
\hline
\end{tabular}
Report of Emotional Support Receipt ( $N=2,138$ Couple-Days)
$(-.5, .5)$, distress on day $t$ had the sample mean subtracted, and the dependent variable was change in distress from day $t$ to day $t+1$ (see Aiken \& West, 1991, for a discussion of the desirability of this type of coding in regression analyses involving interaction effects). Given that change in distress for Day 32 would involve using data obtained on the day after the examination had ended, we omitted Day 32 from the analysis. ${ }^{5}$ The number of couple-days available for analysis was reduced from 2,138 to 2,072 .

\section{Anxiety}

In the left-hand side of Table 2 are the estimates for Equation 1 for anxiety. ${ }^{6}$ The intercept indicates that for average days (average in terms of initial anxiety, phase, and support provision and receipt), anxiety increased by 0.14 units from one day to the next, $t(67)=3.22, p=.002$. The phase effect indicates that, on average, this increase in anxiety was 0.40 units higher in the high-stress than in the moderate-stress phase, $t(67)=9.57, p=.000$. There was no evidence that, averaging over stressor phase, support provision on a given day predicted subsequent declines in anxiety, $b=-0.04, t(67)=-0.94, p=.350$, nor was there evidence that this effect varied by stressor phase, $b=-0.03, t(67)=-0.32$, $p=.748$.

There was evidence, however, that support receipt on a given day predicted subsequent increases in anxiety, $b=0.12$, $t(67)=2.29, p=.025$, and that this effect varied by stressor phase, $b=0.17, t(67)=2.02, p=.047$. Specifically, when recipients reported receiving support on a given day, the likelihood

\footnotetext{
${ }^{3}$ The more usual type of effect coding in linear models is -1 , 1 , but $-.5, .5$ has the advantage of making the coefficient for the effect-coded variable more interpretable. With $-1,1$, the coefficient is interpreted as half the mean difference in the dependent variable associated with the two categories of the predictor variable. With $-.5, .5$, the coefficient is simply the mean difference itself.

${ }^{4}$ In preliminary analyses, we examined whether the estimates for Equation 1 differed depending on whether the examinee was male or female. No evidence of gender differences emerged. Also, we initially estimated models that included (a) a two-way interaction between support provision and receipt and (b) a three-way interaction between support provision, support receipt, and stressor phase. Neither of these effects was statistically significant.

${ }^{5}$ Distress on Days 33 to 35 was very low compared with distress at any point during the previous 32 days (see Thompson \& Bolger, 1999); thus, we did not wish to confound support effects on Day 32 with the sharp decline in distress associated with the end of the examination.

${ }^{6}$ We noted earlier that our analysis approach allowed for each couple to have unique estimates of the coefficients in Equation 1. However, results showed that only three of the coefficients differed across couples: the intercept $\left(b_{0}\right)$, the coefficient for today's dependent variable $\left(b_{1}\right)$, and the coefficient for support receipt $\left(b_{4}\right)$. The standard deviations of these differences were $0.306,0.147$, and 0.229 , respectively. In a multilevel model such as this, in which some coefficients vary randomly across couples and some are fixed, tests of significance for the fixed coefficients can be based on the degrees of freedom for days, 1,864, rather than for couples, 67. Clearly, using the former degrees of freedom would result in smaller $p$ values in significance tests. This approach presumes that the coefficients truly do not vary in the population, but it is known that power to detect such random effects is small in many empirical studies (Kenny et al., 1998). Therefore, we chose to take a conservative approach to significance testing and used a $d f$ of 67 for tests on all coefficients.
} 
Table 2

Effects of Emotional Support Provision and Receipt on Adjustment to the Bar Examination: Multilevel Model Results for Examinee Daily Anxiety and Depression $(N=68$ Couples [2,072 Couple-Days])

\begin{tabular}{|c|c|c|c|c|c|c|}
\hline \multirow[b]{2}{*}{ Predictor on day $t$} & \multicolumn{3}{|c|}{$\begin{array}{c}\text { Change in anxiety } \\
\text { from day } t \text { to day } t+1\end{array}$} & \multicolumn{3}{|c|}{$\begin{array}{l}\text { Change in depression } \\
\text { from day } t \text { to day } t+1\end{array}$} \\
\hline & $b$ & $t(67)$ & $p$ & $b$ & $t(67)$ & $p$ \\
\hline Intercept & 0.14 & 3.22 & .002 & 0.01 & 0.38 & .702 \\
\hline Initial anxiety/depression & -0.50 & -18.30 & .000 & -0.62 & -18.36 & .000 \\
\hline Stressor phase & 0.40 & 9.57 & .000 & 0.07 & 2.38 & .020 \\
\hline Support provision & -0.04 & -0.94 & .350 & -0.07 & -2.67 & .008 \\
\hline Support receipt & 0.12 & 2.29 & .025 & 0.04 & 1.57 & .117 \\
\hline Provision $\times$ Phase & -0.03 & -0.32 & .748 & -0.18 & -3.45 & .001 \\
\hline Receipt $\times$ Phase & 0.17 & 2.02 & .047 & 0.13 & 2.59 & .010 \\
\hline
\end{tabular}

Note. The analysis is based on the 31 days up to and including the examination. Stressor phase contrasts the final week (Days 26-31) with the previous 25 days (Days 1-25). Emotional support provision and receipt and stressor phase are effect-coded variables $(-.5, .5)$. The initial level of anxiety/depression has the sample mean (across couples and days) subtracted.

of their anxiety increasing the following day was 0.17 units greater in the high-stress phase than in the moderate-stress phase.

These estimates can be used to calculate the separate effect of support provision and receipt in each stressor phase. ${ }^{7}$ In the moderate-stress phase, support effects of either kind are negligible: provision $b=-0.03, t(67)=-0.73, p=.467$; receipt $b=0.04$, $t(67)=0.81, p=.418$. In the high-stress phase, the provision effect is once again negligible, $b=-0.06, t(67)=-0.73, p=$ .468 , but the receipt effect is substantial and statistically significant, $b=0.21, t(67)=2.53, p=.014 .^{8}$

Figure 2 shows predicted mean anxiety change for various combinations of provision and receipt in the high-stress phase. Consistent with the effects reported above, examinee reports of emotional support receipt are associated with larger anxiety increases, whereas partner reports of support provision are associated with smaller (and nonsignificant) anxiety increases. Interestingly, although the effects of provision were not significant, note that the lowest levels of anxiety increase were found in the invisible support condition, that is, the condition involving provision but no receipt.

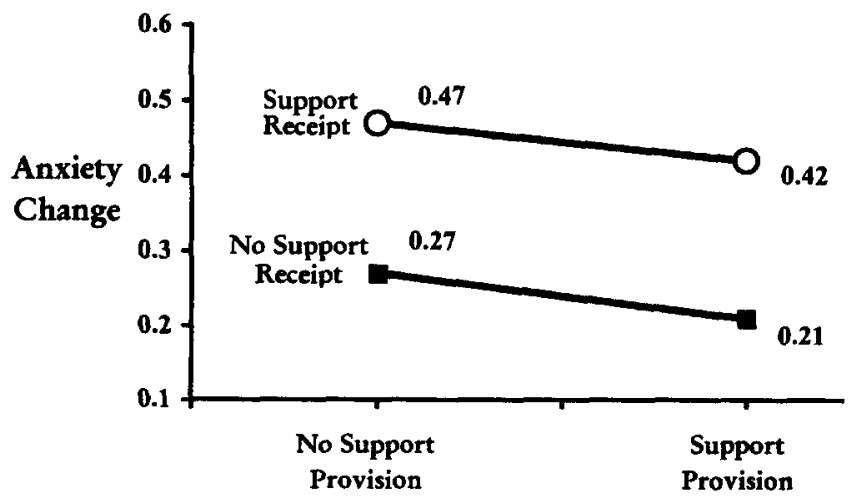

Figure 2. Emotional support effect in the high-stress phase: anxiety.

\section{Depression}

The results for depression are presented in the right-hand side of Table 2. ${ }^{9}$ The intercept shows that for days that were average in terms of initial depression, phase, and support provision and receipt, depression did not increase from one day to the next, $b=$ $-0.01, t(67)=0.38, p=.702$. The phase effect shows that, on average, the day-to-day increase in depression was 0.07 units higher in the high-stress phase than the moderate-stress phase. Averaging across phase, support provision predicted relative declines in depression over time, $b=-0.07, t(67)=-2.67, p=$ .008 , and this effect was greater in the high-stress as compared with the moderate-stress phase, $b=-0.18, t(67)=-3.45, p=$

\footnotetext{
${ }^{7}$ Given the coding used in the analysis, the support provision effect in Phase 1 , for example, is the main-effect coefficient for provision $\left(b_{3}\right)$ minus 0.5 times the Provision $\times$ Phase interaction coefficient $\left(b_{5}\right)$, that is, $-0.04-0.5(-0.03)=-0.03$.

${ }^{8}$ Our analysis approach emphasized the unique effects of provision and receipt, but it could be argued that what is common in these reports is a more valid measure of support actually exchanged. To take account of this concern, we conducted a parallel set of analyses in which, instead of provision and receipt as predictors, we used (a) the mean of the provision and receipt (a measure of what is common to the two reports) and (b) the difference between provision and receipt (a measure of discrepancy). Although it may not be obvious, this parallel analysis explains exactly the same variance in the dependent variables. For anxiety, what this analysis revealed is that the mean of provision and receipt is relatively unimportant; rather, what is important is the extent to which provision is greater than receipt. In the high-stress phase, the effect of the mean of provision and receipt was $0.08, t(67)=1.54, p=.128$, whereas the effect of the difference (provision minus receipt) was $-0.27, t(67)=-2.20, p=.032$.

${ }^{9}$ As in the case of anxiety, only three of the seven coefficients in Equation 1 varied across couples: the intercept $\left(b_{0}\right)$, the coefficient for today's depression $\left(b_{1}\right)$, and the coefficient for phase $\left(b_{3}\right)$. The standard deviations of these couple differences were $0.251,0.191$, and 0.123 , respectively. Once again we took a conservative approach to significance testing and used the degrees of freedom for couples, 67 , for tests on all coefficients.
} 
.001 . Averaging across phase, there was some evidence that support receipt predicted a relative increase in depression over time, $b=0.04, t(67)=1.57, p=.117$, and this effect was greater in the high-stress compared with the moderate-stress phase, $b=0.13$, $t(67)=2.59, p=.010$.

Once again, it is useful to examine the provision and receipt effects in each stressor phase. In the moderate-stress phase, support effects of either kind are again negligible: provision $b=0.01$, $t(67)=0.61, p=.544$; receipt $b=-0.02, t(67)=-0.92, p=$ .362 . In the high-stress phase, however, both effects are substantial, opposite in sign, and statistically significant: provision $b=$ $-0.16, t(67)=-3.41, p=.001$; receipt $b=0.11, t(67)=2.31$, $p=.024$. Thus, in the high-stress phase, when partners reported providing support on a given day, the change in recipients' depression from that day to the next was 0.16 units lower than it was when partners did not report providing support. By contrast, when recipients reported receiving support on a given day, the change in their depression was 0.11 units higher than it was when they did not report receiving support. ${ }^{10}$

Figure 3 shows predicted mean depression change for various combinations of provision and receipt in the high-stress phase. The extremes in the figure are most notable. The best situation is the one we would label as invisible support, in which partners said they provided emotional support but examinees said they did not receive it. In this situation, depression tended to decrease over time by 0.09 units, $t(67)=-1.73, p=.088$. The worst situation was one in which providers said they did not provide support but recipients said they received it. Here, examinees experienced the costs of receipt, failed to experience the benefits of provision, and their depression increased by 0.18 units, $t(67)=3.30, p=.002$.

\section{Discussion}

This research helps resolve a puzzle in the social support literature: Although the perception that support is available is associated with better adjustment, the perception that one has been the recipient of specific supportive acts is not. Given that individual supportive acts are the presumed building blocks of generalized beliefs about support availability, why do such acts not appear to benefit the recipient? Our findings suggest that such acts do, in

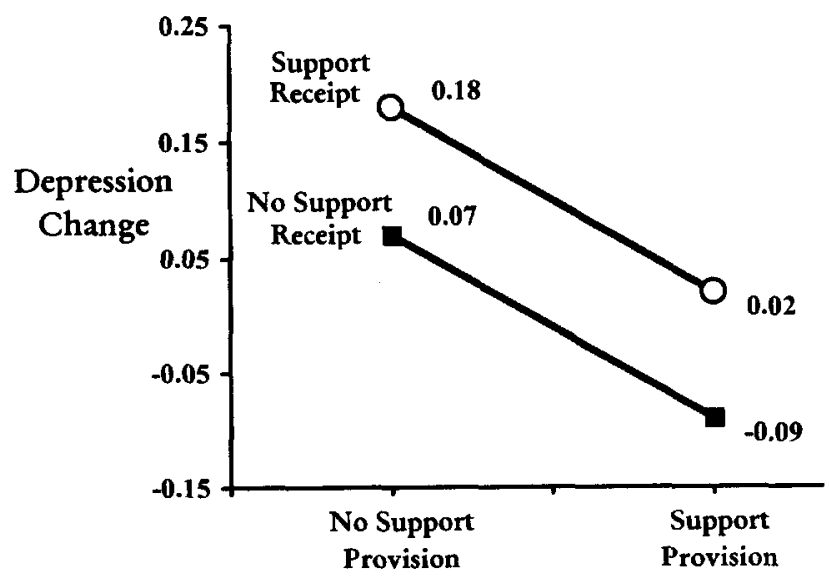

Figure 3. Emotional support effect in the high-stress phase: depression. fact, benefit the recipient. However, relying solely on recipients' reports of support receipt masks this beneficial effect, because there is a cost to adjustment of feeling that one has received support.

Specifically, using a daily diary design to study couples in which one member was preparing for the New York State Bar Examination, we obtained the examinee's reports of receiving emotional support from the partner and the partner's reports of providing emotional support to the examinee. By capitalizing on the fact that couples' reports of provision and receipt did not always agree, it was possible in the case of depression to show that reports of support provision were associated with increased examinee adjustment, whereas reports of support receipt were associated with decreased examinee adjustment. Thus, these results suggest that the most beneficial support is that which is invisible to the recipient. In this situation, the recipient reaps the benefits of support provision without incurring the cost of support receipt.

Whereas the hypothesized pattern was found for depression, only part of the pattern was found for anxiety. Emotional support receipt increased anxiety, but emotional support provision did not decrease anxiety. How can one make sense of this pattern? The ineffectiveness of support in alleviating anxiety is interpretable if one considers the high degree of threat posed by the bar examination. Because so much career success is at stake, this event is considered highly stressful by almost all who take it. Thus, for an event as threatening as this, there may be little partners can do to lower the anticipatory anxiety it provokes. However, it does appear that partners can help alleviate symptoms of anticipatory depression and discouragement.

It is important to note that the pattern of results found here cannot be explained by processes involving unmeasured stressor severity or miscarried helping. Although the null or negative effects of support receipt found in previous studies could have been due to unmeasured differences in stressor severity, this seems unlikely in the current study because the stressor was objectively the same for each participant. Similarly, our results are inconsistent with the idea of miscarried helping, whereby the provider's efforts to be helpful are perceived as unhelpful and thus unlikely to be coded as support (Coyne et al., 1988). Recall that this is precisely the situation we labeled invisible support and one that we found to be associated with the lowest distress. If miscarried helping was a common form of invisible support then it seems unlikely we would have found the results we did.

\section{Issues for Future Research}

These findings raise several important issues for future research. First, whereas the findings help explain why traditional measures of enacted support (those based on recipient accounts) fail to

\footnotetext{
${ }^{10}$ Again we conducted a parallel analysis that estimated the effects of the mean support and the discrepancy in support (provision minus receipt). This analysis revealed results similar to those found for anxiety: The average level of support was unimportant in predicting depression; rather, depression declined most when providers' accounts of support exceeded those of recipients. For depression in the high-stress phase, the effect of the mean of provision and receipt was $-0.03, t(67)=-0.87, p=.386$, whereas the effect of the difference (provision minus receipt) was -0.27 , $t(67)=-3.63, p=.001$.
} 
buffer the effects of stressors on adjustment, they do not explain the beneficial effects of perceived support availability. Some have suggested that perceptions of support availability are an aspect of personality and may have little bearing on how much support has been received in the recent past (Lakey \& Cassady, 1990; Sarason, Pierce, \& Sarason, 1990). Our findings, however, leave open the possibility that perceived support availability measures capture, to some extent, support that has been provided. Thus, it will be important in future research to examine the relation between perceived support availability and partner reports of support provision, especially of invisible support provision.

Second, we have not directly examined why the perception that one has been supported is associated with heightened distress. It has been suggested that the receipt of aid can entail a self-esteem cost to the extent that it challenges the recipient's sense of personal competence in a valued domain. A number of classic laboratory studies bolster this view (Fisher et al., 1982; Shapiro, 1978). Support receipt can also amplify distress by making recipients aware that their distress and incompetence are publicly visible, thereby prompting concern that others will evaluate them negatively. Finally, it is possible that support receipt may have a negative effect by unintentionally drawing recipients' attention toward rather than away from their negative mood. In so doing, it may increase the impact of the negative mood on subsequent cognitions and behavior, thereby leading to an increasing spiral of negativity. Future studies will need to assess the extent to which these possible explanations can account for the effects reported here.

Third, it is important to reiterate that we do not believe that invisible support, as identified in this study, is a single type of support. Rather, we believe that it involves at least two types. The first is composed of acts that are beneficial to the recipient but which occur outside of the recipient's awareness. That is, the provider does something in the background that the recipient never finds out about, such as dealing with problems that would have distressed the recipient had he or she known about them or had to deal with them. This type of support has been referred to by Coyne as protective buffering (see, e.g., Coyne \& Smith, 1991). The data were not available in our study to determine what proportion of invisible support is of this type, but such data could be obtained in future daily diary studies.

The second type of invisible support is one that is accomplished in such a skillful way that, although information about the transaction is available to the recipient, the transaction is not coded as enacted support. Because the supportive act is not made salient, recipients avoid the accompanying increase in the salience of their distress, their doubts about their competence in the problem domain, and their perception that their distress and incompetence are publicly visible. This type of invisible support, whereby information that support has been given is available but is not coded as received, is likely to characterize the expert face-to-face social support that is the essence of good parenting, good mentoring, and good friendships, and being a good clinician or social worker.

What is involved in such expert support? Politeness theory (P. Brown \& Levinson, 1987) provides one potential answer, suggesting that such support is indirect, which involves providing support without drawing attention to the recipient's need. For example, indirect instrumental support might involve providing the solution to an instrumental problem in such a way that recipients think they have discovered it themselves. Indirect emotional support might involve acknowledging the normatively distressing nature of the recipient's situation and highlighting how others are coping more poorly or commenting on something positive about the recipient. Assessing whether such indirect support underlies the effects reported here is an important topic for future investigation. It would be interesting to establish whether skillful support providers disguise their support efforts by providing support in indirect ways. Similarly, it would be interesting to determine whether skillful support recipients interpret helpful actions in ways that downplay the recipient's sense of indebtedness or ineptitude.

Our focus in this article has been on supportive acts that providers code as support but recipients do not. However, supportive acts that neither party code as support may most closely approximate what Lieberman (1986) had in mind when he described effective support as support that occurs so smoothly that people may not be aware of it. Clearly, with our current methodology we are unable to identify this type of daily support. We have no way of knowing how common such interactions are or whether they exert a particularly beneficial effect on adjustment. We suspect, however, that they occur frequently, particularly in communal relationships such as marriages (Clark \& Reis, 1988) and in companionate relationships, that is, relationships that are sources of pleasurable shared activities (Coyne \& Bolger, 1990; Rook, 1987, 1990). To study such support processes it may be necessary to use behavioral observation methods, an approach that is rare in the support literature (see Cutrona \& Suhr, 1994; Pasch \& Bradbury, 1998, for exceptions).

Future research will also need to establish the generalizability of our findings. It may be that certain types of stressors are more likely to elicit invisible support than others do. It is plausible to expect that emotional support is more likely to be invisible than is instrumental support, but future analyses may show that this is not the case. Moreover, there may be individual differences in the extent to which invisible support is beneficial. For example, although there are important gender differences in stress and support processes (Taylor et al., 2000), our sample of female examinees $(N=23)$ may have been too small to detect them. It is also known that support processes vary as a function of personality (e.g., Nolen-Hoeksema \& Davis, 1999), and it will be important to consider this source of heterogeneity in future research.

\section{Caveats and Conclusions}

This study has a number of important limitations. First, we have relied on support-provider and support-recipient accounts of support transactions. We have no way of knowing the accuracy of these accounts or whether providers are more or less accurate than recipients. It is likely that both are fallible reporters and that this explains some of the discrepancies between their accounts.

Second, an inherent problem in diary studies is that to reduce time demands on participants, less-than-ideal measures of constructs must be used. In the case of emotional support, this has led us to use a crude single-item measure. Although we have no direct measure of its reliability and validity, it is clear that if it had been completely unreliable we would not have found any effects of our measures of distress. The question of validity is more difficult to answer, except to say that the content of the support item has face validity and the wording is similar to items used in the well- 
validated Inventory of Socially Supportive Behaviors developed by Barrera and his colleagues (Barrera, Sandler, \& Ramsay, 1981).

Third, we have focused on support processes over a relatively short period of time, 32 days, and we have used day-to-day changes in distress as our outcome variable. Thus, we were not able to examine longer term support processes or how these might matter for longer term emotional functioning.

Despite these limitations, we have documented that social support processes are a good deal more complex than previously considered in empirical research on enacted support. In particular, our data suggest that the most effective support transactions may also be the most subtle. This finding poses both methodological and conceptual challenges and raises a wide variety of questions that should be the focus of future investigation.

\section{References}

Abbey, A., Andrews, F. M., \& Halman, L. J. (1995). Provision and receipt of social support and disregard: What is their impact on the marital life quality of infertile and fertile couples? Journal of Personality and Social Psychology, 68, 455-469.

Aiken, L. S., \& West, S. G. (1991). Multiple regression: Testing and interpreting interactions. Thousand Oaks, CA: Sage.

Antonucci, T. C., \& Israel, B. A. (1986). Veridicality of social support: A comparison of principal and network members' responses. Journal of Consulting and Clinical Psychology, 54, 432-437.

Barrera Jr., M. (1986). Distinctions between social support concepts, measures, and models. American Journal of Community Psychology, 14, 413-445.

Barrera Jr., M., Sandler, I. N., \& Ramsay, T. B. (1981). Preliminary development of a scale of social support: Studies on college students. American Journal of Community Psychology, 9, 435-447.

Bolger, N., \& Eckenrode, J. (1991). Social relationships, personality, and anxiety during a major stressful event. Journal of Personality and Social Psychology, 61, 440-449.

Bolger, N., Foster, M., Vinokur, A. D., \& Ng, R. (1996). Close relationships and adjustment to a life crisis: The case of breast cancer. Journal of Personality and Social Psychology, 70, 283-294.

Brown, B. B. (1978). Social and psychological correlates of help-seeking behavior among urban adults. American Journal of Community Psychology, 6, 425-439.

Brown, P., \& Levinson, S. (1987). Politeness: Some universals in language usage. New York: Cambridge University Press.

Bryk, A. S., \& Raudenbush, S. W. (1992). Hierarchical linear models: Applications and data analysis methods. Thousand Oaks, CA: Sage.

Clark, M. S., \& Reis, H. T. (1988). Interpersonal processes in close relationships. Annual Review of Psychology, 39, 609-672.

Cohen, S. (1992). Stress, social support, and disorder. In H. O. F. Veiel \& $\mathrm{U}$. Baumann (Eds.), The meaning and measurement of social support (pp. 109-124). New York: Hemisphere.

Cohen, S., \& Wills, T. A. (1985). Stress, support, and the buffering hypothesis. Psychological Bulletin, 98, 310-357.

Coriell, M., \& Cohen, S. (1995). Concordance in the face of a stressful event: When do members of a dyad agree that one person supported the other? Journal of Personality and Social Psychology, 69, 289-299.

Coyne, J. C., \& Bolger, N. (1990). Doing without social support as an explanatory concept. Journal of Social and Clinical Psychology, 9, $148-158$.

Coyne, J. C., \& Smith, D. A. F. (1991). Couples coping with myocardial infarction: A contextual perspective on wives' distress. Journal of Personality and Social Psychology, 61, 404-412.

Coyne, J. C., Wortman, C. B., \& Lehman, D. R. (1988). The other side of support: Emotional overinvolvement and miscarried helping. In B. H.
Gottlieb (Ed.), Marshaling social support (pp. 305-330). Thousand Oaks, CA: Sage.

Cutrona, C. E. (1986). Behavioral manifestations of social support: A microanalytic investigation. Journal of Personality and Social Psychology, 51, 201-208.

Cutrona, C. E., \& Suhr, J. A. (1994). Social support communication in the context of marriage: An analysis of couples' supportive interactions. In B. R. Burleson, T. L. Albrecht, \& I. G. Sarason (Eds.), Communication of social support: Messages, interactions, relationships, and community (pp. 113-135). Thousand Oaks, CA: Sage.

Dunkel-Schetter, C., \& Bennett, T. L. (1990). Differentiating the cognitive and behavioral aspects of social support. In B. R. Sarason, I. G. Sarason, \& G. R. Pierce (Eds.), Social support: An interactional view (pp. 267-296). New York: Wiley.

Eckenrode, J. (1983). The mobilization of social supports: Some individual constraints. American Journal of Community Psychology, 11, 509-528.

Eckenrode, J., \& Bolger, N. (1997). Daily and within-day event measurement. In S. Cohen, R. C. Kessler, \& L. U. Gordon (Eds.), Measuring stress: A guide for health and social scientists (pp. 80-101). New York: Oxford University Press.

Eckenrode, J., \& Wethington, E. (1990). The process and outcome of mobilizing social support. In S. W. Duck \& R. C. Silver (Eds.), Personal relationships and social support (pp. 83-103). Thousand Oaks, CA: Sage.

Fisher, J. D., Nadler, A., \& Whitcher-Alagna, S. (1982). Recipient reactions to aid. Psychological Bulletin, 91, 27-54.

Goldstein, H. (1995). Multilevel statistical models (2nd ed.). New York: Wiley.

Gottlieb, B. H. (1988). Marshaling social support: The state of the art in research and practice. In B. H. Gottlieb (Ed.), Marshaling social support. Thousand Oaks, CA: Sage.

Heller, K., Swindle, R. W., \& Dusenbury, L. (1986). Component social support processes: Comments and integration. Journal of Consulting and Clinical Psychology, 54, 466-470.

Hobfoll, S. E., \& Vaux, A. (1993). Social support: Social resources and social context. In L. Goldberger \& S. Breznitz (Eds.), Handbook of stress (pp. 685-705). New York: Free Press.

House, J. S., Landis, K. R., \& Umberson, D. (1988). Social relationships and health. Science, 241, 540-545.

Kenny, D. A., Kashy, D., \& Bolger, N. (1998). Data analysis in social psychology. In D. T. Gilbert, S. T. Fiske, \& G. Lindzey (Eds.), Handbook of social psychology (4th ed.; Vol. 1, pp. 233-265). Boston: McGraw-Hill.

Kessler, R. C., \& Greenberg, D. F. (1981). Linear panel analysis: Models of quantitative change. New York: Academic Press.

Kreft, I. G. G., \& De Leeuw, J. (1998). Introducing multilevel modeling. Thousand Oaks, CA: Sage.

Lakey, B., \& Cassady, P. B. (1990). Cognitive processes in perceived social support. Journal of Personality and Social Psychology, 59, 337343.

Lieberman, M. A. (1986). Social supports-the consequences of psychologizing: A commentary. Journal of Consulting and Clinical Psychology, 54, 461-465.

Littell, R. C., Milliken, G. A., Stroup, W. W., \& Wolfinger, R. D. (1996). SAS system for mixed models. Cary, NC: SAS Institute.

Lorr, M., \& McNair, D. M. (1971). The Profile of Mood States manual. San Diego, CA: Educational and Industrial Testing Service.

Nolen-Hoeksema, S., \& Davis, C. G. (1999). "Thanks for sharing that": Ruminators and their social support networks. Journal of Personality and Social Psychology, 77, 801-814

Pasch, L. A., \& Bradbury, T. N. (1998). Social support, conflict, and the development of marital dysfunction. Journal of Consulting and Clinical Psychology, 66, 219-230.

Reis, H. T. (1984). Social interaction and well-being. In S. Duck (Ed.), 
Personal relationships V: Repairing personal relationships. New York: Academic Press.

Rook, K. S. (1987). Social support versus companionship: Effects on life stress, loneliness, and evaluations by others. Journal of Personality and Social Psychology, 52, 1132-1147.

Rook, K. S. (1990). Social relationships as a source of companionship: Implications for older adults' psychological well-being. In B. R. Sarason, I. G. Sarason, \& G. R. Pierce (Eds.), Social support: An interactional view (pp. 219-250). New York: Wiley.

Sarason, B. R., Pierce, G. R., \& Sarason, I. G. (1990). Social support: The sense of acceptance and the role of relationships. In B. R. Sarason, I. G. Sarason, \& G. R. Pierce (Eds.), Social support: An interactional view (pp. 97-128). New York: Wiley.

Sarason, B. R., Sarason, I. G., \& Gurung, R. A. R. (1997). Close personal relationships and health outcomes: A key to the role of social support. In S. Duck (Ed.), Handbook of personal relationships (2nd ed., pp. 547573). New York: Wiley.

SAS Institute. (1997). SAS/STAT software: Changes and enhancements through release 6.12. Cary, NC: Author.

Shapiro, E. G. (1978). Embarrassment and help-seeking. In B. M. DePaulo, A. Nadler, \& J. D. Fisher (Eds.), New directions in helping: Vol. 2. Help-seeking (pp. 143-164). New York: Academic Press.

Snijders, T. A. B., \& Bosker, R. J. (1999). Multilevel analysis: An intro- duction to basic and advanced multilevel modeling. Thousand Oaks, CA: Sage.

Stroebe, W., \& Stroebe, M. (1996). The social psychology of social support. In E. T. Higgins \& A. W. Kruglanski (Eds.), Social psychology: Handbook of basic principles (pp. 597-621). New York: Guilford Press.

Taylor, S. E., Klein, K. C., Lewis, B. P., Gruenewald, T. L., Gurung, R. A. R., \& Updegraff, J. A. (2000). Biobehavioral responses to stress in females: Tend-and-befriend, not fight-or-flight. Psychological Review, 107, 411-429.

Thompson, A., \& Bolger, N. (1999). Emotional transmission in couples under stress. Joumal of Marriage and the Family, 61, 38-48.

Wethington, E., \& Kessler, R. C. (1986). Perceived support, received support, and adjustment to stressful life events. Joumal of Health and Social Behavior, 27, 78-89.

Wills, T. A. (1990). Social support and interpersonal relationships. In M. S Clark (Ed.), Review of personality and social psychology (Vol. 12, pp. 265-289). Thousand Oaks, CA: Sage.

Received October 6, 1997

Revision received June 1, 2000

Accepted June 1, 2000 